\title{
Misoprostol Vaginal Insert in Labor Induction: A Cost-Consequences Model for 5 European Countries-An Economic Evaluation Supported with Literature Review and Retrospective Data Collection
}

Adam Bierut · Jadwiga Dowgiałło-Smolarczyk • Izabela Pieniążek • Jarosław Stelmachowski •

Kinga Pacocha $\cdot$ Maciej Sobkowski $\cdot$ Oleg R. Baev · Jacek Walczak

Received: June 15, 2016 / Published online: August 22, 2016

(C) The Author(s) 2016. This article is published with open access at Springerlink.com

\section{ABSTRACT}

Introduction: The present study aimed to assess the costs and consequences of using an innovative medical technology, misoprostol vaginal insert (MVI), for the induction of labor (IOL), in place of alternative technologies used as a standard of care.

Methods: This was a retrospective study on cost and resource utilization connected with

Enhanced content To view enhanced content for this article go to http://www.medengine.com/Redeem/ ABE4F06039CDBBF9.

Electronic supplementary material The online version of this article (doi:10.1007/s12325-016-0397-3) contains supplementary material, which is available to authorized users.

A. Bierut · J. Dowgiałło-Smolarczyk

Ferring Pharmaceuticals Poland Sp. z o. o., Warsaw, Poland

I. Pieniążek $(\bowtie) \cdot J$. Stelmachowski · K. Pacocha ·

J. Walczak

Arcana Institute, Krakow, Poland

e-mail: ipieniazek@inar.pl

M. Sobkowski

Gynecological and Obstetrics Clinical Hospital of

Poznan Medical Science University, Poznan, Poland

O. R. Baev

Research Center for Obstetrics, Gynecology and

Perinatology, Moscow, Russia economic model development. Target population were women with an unfavorable cervix, from 36 weeks of gestation, for whom IOL is clinically indicated. Data on costs and resources was gathered via a dedicated questionnaire, delivered to clinical experts in five EU countries. The five countries participating in the project and providing completed questionnaires were Austria, Poland, Romania, Russia and Slovakia. A targeted literature review in Medline and Cochrane was conducted to identify randomized clinical trials meeting inclusion criteria and to obtain relative effectiveness data on MVI and the alternative technologies. A hospital perspective was considered as most relevant for the study. The economic model was developed to connect data on clinical effectiveness and safety from randomized clinical trials with real life data from local clinical practice.

Results: The use of MVI in most scenarios was related to a reduced consumption of hospital staff time and reduced length of patients' stay in hospital wards, leading to lower total costs with MVI when compared to local comparators. 
Conclusions: IOL with the use of MVI generated savings from a hospital perspective in most countries and scenarios, in comparison to alternative technologies.

Funding: Sponsorship, article processing charges, and the open access charge for this study were funded by Ferring Pharmaceuticals Poland.

Keywords: Cost consequences analysis; Misoprostol vaginal insert; MVI; Labor induction; Reproduction

\section{INTRODUCTION}

Induction of labor (IOL) is the initiation of contractions of the uterus in a pregnant woman who is not in labor, to help achieve a vaginal birth within $24-48 \mathrm{~h}$. Indications and contraindications for IOL are provided in numerous clinical guidelines [1].

Many products are currently available in clinical practice to induce labor [prostaglandins E2: dinoprostone cervical gel (Dgel), dinoprostone vaginal insert (DVI), dinoprostone tablets (Dtab); oxytocin and mechanical methods including Foley or Cook catheters]. Misoprostol vaginal insert (MVI) is a new product containing a synthetic analog of natural prostaglandin E1, which is indicated for IOL in women with an unfavorable cervix, from 36 weeks of gestation, for whom IOL is clinically indicated [2].

The primary objective of the research was to compare the total healthcare costs in Austria, Poland, Romania, Russia and Slovakia related to the IOL using MVI with the relevant alternatives. A cost-consequences model was developed to assess MVI versus other technologies used as the standard of care (SOC) in IOL.

\section{METHODS}

A decision model was developed to assess the costs and consequences related to MVI use in place of alternative technologies in IOL. The economic model used retrospective data on unit costs and resource utilization related to IOL in local clinical practice from five countries (data was collected separately for each country via a dedicated questionnaire) and relative effectiveness data on MVI versus comparators, with efficacy and safety data retrieved from a literature review.

\section{Clinical Data}

A literature review was performed, based on the Population, Intervention, Comparator, Outcomes, Study (PICOS) scheme, to assess the relative effectiveness of MVI versus alternatives. The literature search was conducted in Medline via PubMed and the Cochrane Library. The manuscript reviews all of the appropriate randomized controlled trials (RCTs) in the literature review.

Where possible, data from RCTs was pooled and meta-analysis was conducted. Cochrane Collaboration guidelines were applied [3] for quantitative analysis. To account for heterogeneity, a random-effects model was used. Heterogeneity of results was assessed using Q Cochran and $I^{2}$ statistical tests (StatsDirect software, version 2.6.8; StatsDirect Limited, Cheshire, UK) [4].

Direct comparison of MVI versus DVI and indirect comparison (Bucher's method) via a common comparator (DVI), for MVI vs Dgel, Dtab and Foley $[5,6]$ were applied.

In case of oxytocin only, naïve indirect comparison was possible. Because of many limitations of this kind of approach, we 
resigned from presenting results for this comparison $[7,8]$.

Relative risk (RR) was chosen as the parameter to assess clinical effectiveness and safety. The following outcomes were assessed: proportion of patients with vaginal delivery, proportion of patients with oxytocin use, proportion of patients with adverse events (uterine tachysystole, tocolytic administration, meconium in amniotic fluid, chorioamnionitis, and postpartum hemorrhage).

Reduction (or increase) in time from induction to labor and in time of labor due to MVI use versus comparators, was calculated on the basis of clinical data. Total time from induction to delivery and total time of labor for comparators were included in the model, as reported in country-specific questionnaires and reflecting local clinical practice.

\section{Cost and Resource Use Data: Retrospective Study}

The country-specific data used in the modeling were divided into two domains: costs and resource use. Real-world data (RWD) was obtained from clinical experts for the five countries of interest. A comprehensive questionnaire was constructed in MS Excel 2007 and delivered to key opinion leaders or specialists experienced in gynecology and obstetrics. A macro-costing method was chosen for data reporting. One completed questionnaire was received from each country. The questionnaire sourced data for the average patient, taking into consideration the results of a review of patients' medical cards. After verification of completed questionnaires, all discrepancies were discussed and appropriate data were employed.
The following categories of unit costs were considered:

- Cost of interventions MVI, DVI, Dtab, Dgel and oxytocin;

- Cost of infusion fluid required for dissolving the oxytocin;

- Hourly rates of medical staff (nurse, midwife, obstetrician-gynecologist, anesthesiologist, neonatologist);

- Hourly cost of patient's stay in hospital wards: antenatal, labor (separately for vaginal and cesarean delivery) and postnatal (categories included all costs of procedures, disposables and non-medical resources apart from costs of drugs used for IOL and medical staff costs);

- Costs of adverse event treatment expressed as total, fixed costs of treatment.

Resource use in the model was generally divided into three time periods:

- Time from induction to (active) labor;

- Time of labor;

- Time from delivery to the hospital discharge. The categories of resources (the same in each of mentioned time periods) taken into account in the modeling were as follows:

- Usage of the comparator per patient;

- Usage of supporting oxytocin;

- Usage of infusion fluid required for dissolving oxytocin;

- Time spent per patient by nurse, midwife, obstetrician-gynecologist, neonatologist anesthesiologist;

- Patient's time spent in antenatal, labor and postnatal ward.

All resource use categories were gathered separately for vaginal (and for each of the comparators considered) and cesarean delivery (assuming cesarean delivery as IOL failure). For each item average values per one patient were obtained. 


\section{The Cost-Benefit Model}

The model was designed to connect clinical data on effectiveness and safety from RCTs with RWD on costs and resource utilization from the retrospective questionnaire.

The model assumes that a patient spends time before active labor within the antenatal ward and then enters the labor ward for time in labor. The IOL can end successfully with vaginal delivery or with failure (cesarean delivery). After delivery, the patient and the neonate spend time within the postnatal ward until the hospital discharge.

The main outcomes of the model were: total cost difference of MVI vs comparator (per single patient), proportion of patients with different types of delivery, cost and resource utilization results (presented separately for vaginal and cesarean delivery).

Within the model, the differences in effectiveness and safety between MVI and comparators were applied to patients with IOL, producing differences in resource use and costs. The structure for time to labor and time to delivery is presented in Fig. 1.

\section{Compliance with Ethics Guidelines}

This article is based on previously conducted studies and does not involve any new studies of human or animal subjects performed by any of the authors.

\section{RESULTS}

The retrospective questionnaire indicated that product availability and accepted clinical practice dictate different standards of care in each country. The following comparators were designated by the clinical experts:
1. Austria: DVI, Dtab, oxytocin;

2. Poland: Dgel, oxytocin, Foley catheter;

3. Romania: oxytocin;

4. Russia: Dgel; oxytocin;

5. Slovakia: Dtab; Dgel.

In all countries except Romania, prostaglandins were considered the SOC in the IOL. Oxytocin was used in almost all cases of IOL in Romania as first line therapy (without prior prostaglandins use). Despite the limitations of oxytocin, it was still used by obstetricians in Austria, Poland, Russia and Romania. In the latter, oxytocin was the only option considered for IOL before the launch of MVI.

\section{Results of the Literature Review}

From the literature search, 11 RCTs out of 26 studies were included in the literature review and data synthesis (Wing [9], Facchinetti [10], [11], Marconi [12], Stewart [13], Strobelt [14], Rabl [15], Cromi [16], [17], Edwards [18], Jóźwiak [19]) (Table 1). Although Cromi [16] concerned a double balloon catheter, the study was included, since it was shown that there were no significant differences in effectiveness or safety of ripening with a double balloon catheter when compared to Foley catheter $[20,21]$. Further details on literature review search strategy can be found in supplementary material (S1).

For time-to-event end-points, only trials reporting both time to delivery and time to active labor/labor onset were included in the data synthesis and statistical calculations. This approach ensured reliability of the results. Therefore, trials which assessed only one of the end-points were excluded from the calculations because of the risk of potential bias on the model results. The following trials were eligible for statistical analysis: Wing [9], Facchinetti [11], Rabl [15], Cromi [16] and [17]. 


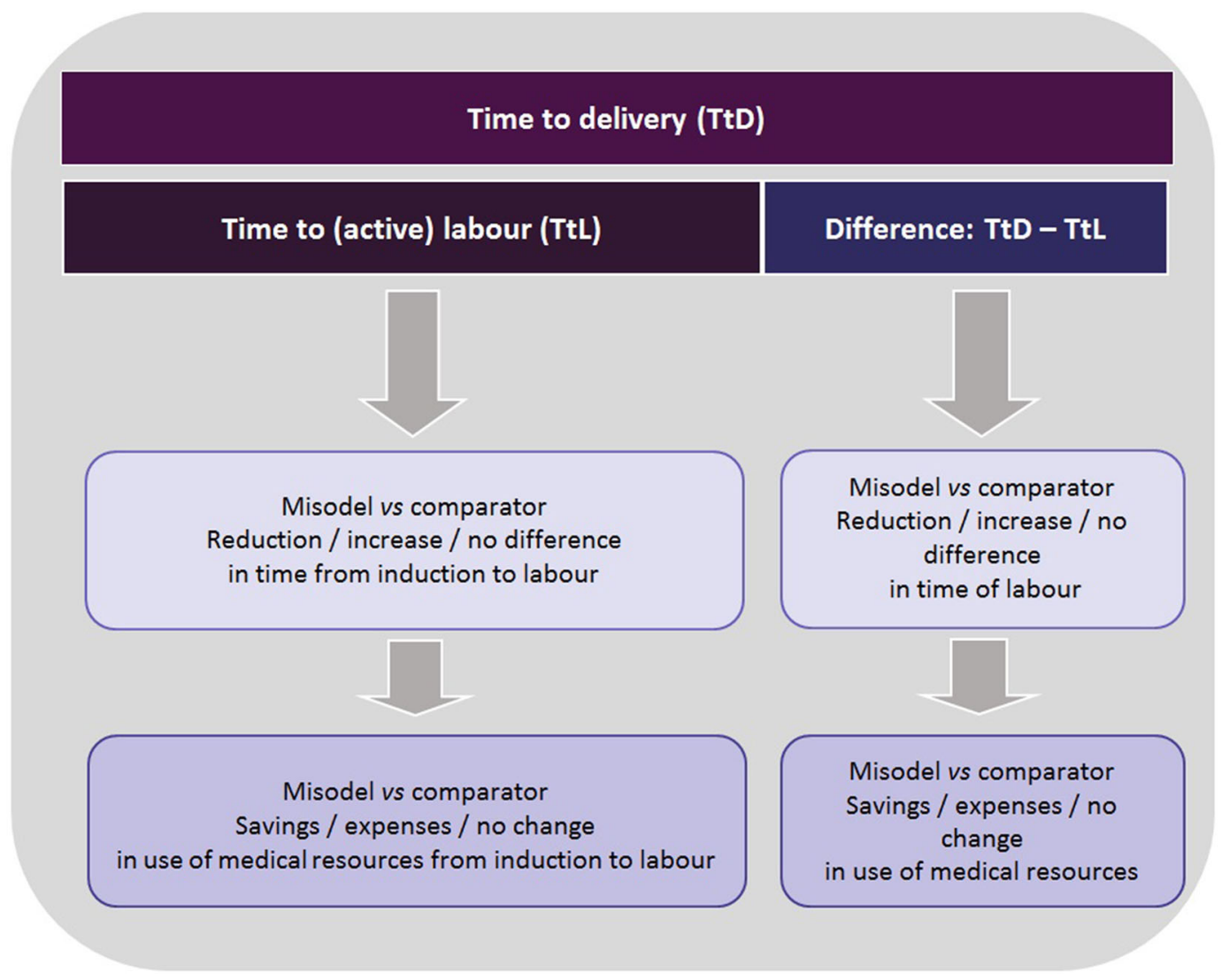

Fig. 1 Scheme of time-to-event end points use in the model calculations

Since there were observed differences in the end points definitions, random effect model was used to perform a statistical analysis.

Results of head-to-head trials showed that for time to delivery and time to active labor, MVI was statistically significantly better than DVI (Wing [9]), DVI was statistically significantly better than Dgel (Facchinetti [11]), DVI was comparable to Dtab (Rabl [15]) and Foley (meta-analysis of Cromi [14] and [17]). Detailed results are presented in Table 2.

To reflect resource utilization of MVI versus the comparator, outcomes based on time-to-event end-points were recalculated as a reduction/increase, presented as the percentage of time (in hours) in the comparator arm. According to the calculations performed, use of MVI was related to a reduction both in time from induction to labor onset and time of labor.

On the basis of RR parameters (Table 3), MVI seems to have similar performance on effectiveness and safety, since the differences in most of the outcomes did not reach statistical significance. Nevertheless, it was shown that MVI was related to significantly lower oxytocin use versus all comparators. Vaginal delivery was observed more often in MVI arm versus DVI, Dgel, and Dtab. Only in case of Foley frequency of vaginal delivery was lower in the MVI group, although this result was not statistically significant.

Unfortunately, adverse events were not widely reported in the trials. Only for one trial, Wing [9], it was possible to present a 


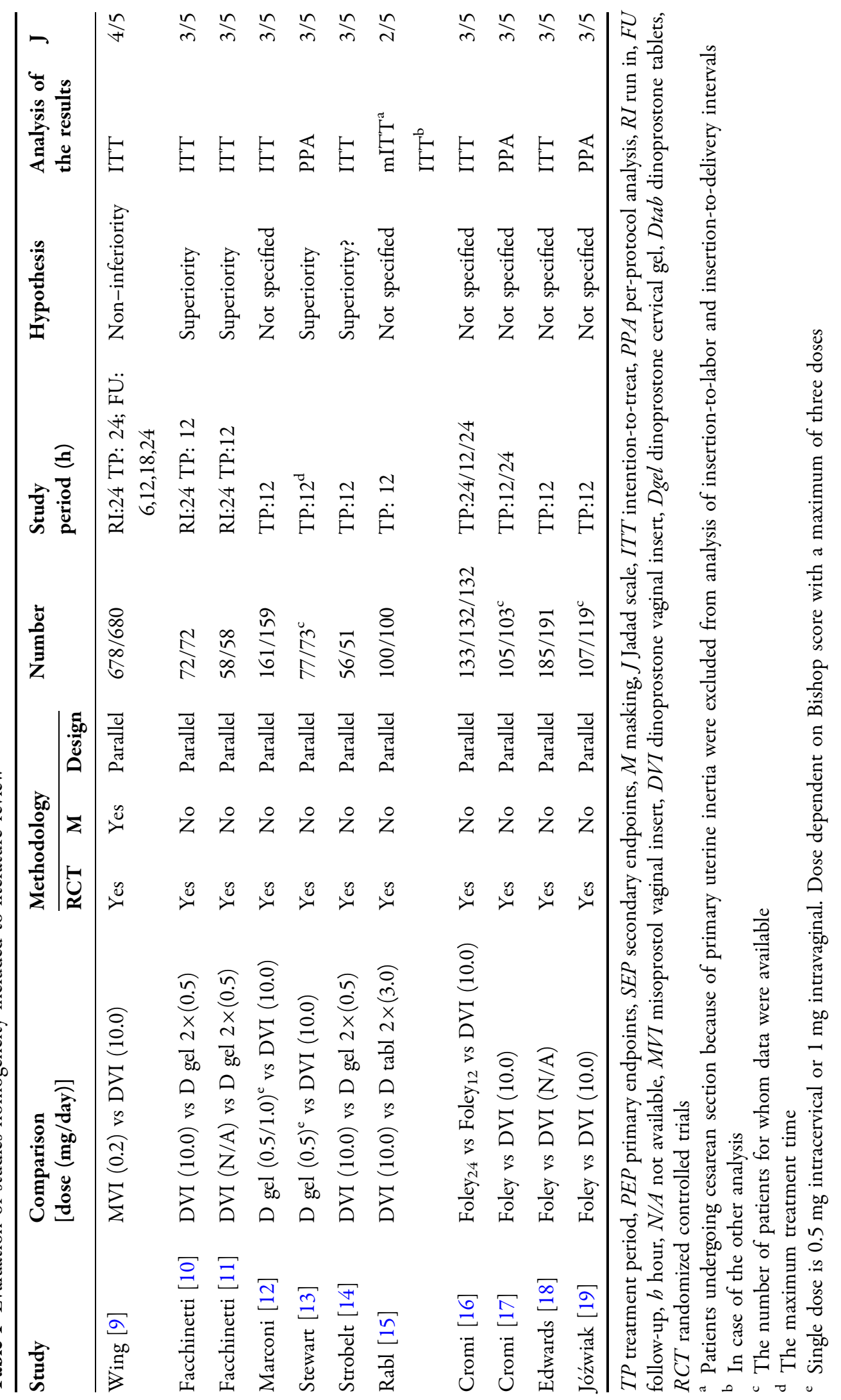


Table 2 Results of analysis of clinical data

\begin{tabular}{|c|c|c|c|c|c|}
\hline \multirow[t]{2}{*}{ Comparison } & \multirow[t]{2}{*}{ Outcome analyzed (h) } & \multirow[t]{2}{*}{ RCT } & \multicolumn{2}{|l|}{$\operatorname{Median}(\mathrm{SE})^{\mathrm{a}}$} & \multirow{2}{*}{$\begin{array}{l}\text { Mean difference } \\
(95 \% \mathrm{CI})^{\mathrm{a}}\end{array}$} \\
\hline & & & Intervention & Comparator (DVI) & \\
\hline \multicolumn{6}{|c|}{ Results of the direct comparisons for time to delivery and time to active labor end-points } \\
\hline \multirow[t]{2}{*}{ MVI vs DVI } & Time to vaginal delivery & Wing $[9]$ & $21.5(0.87)$ & $32.8(1.20)$ & $-11.3(-14.2 ;-8.4)$ \\
\hline & Time to active labor & & $12.1(0.23)$ & $18.6(1.12)$ & $-6.5(-8.7 ;-4.3)$ \\
\hline \multirow[t]{2}{*}{ Dgel vs DVI } & Time to delivery & Facchinetti $[11]$ & $25.3(1.59)$ & $20.5(1.35)$ & $4.8(0.7 ; 8.9)$ \\
\hline & Time to labor onset & & $16.6(1.46)$ & $12.4(0.98)$ & $4.2(0.8 ; 7.6)$ \\
\hline \multirow[t]{2}{*}{ D tab vs DVI } & Time to delivery & Rabl [15] & $15.5(2.32)$ & $17.0(2.62)$ & $-1.5(-8.3 ;-5.3)$ \\
\hline & Time to labor & & $9.0(2.76)$ & $9.8(2.84)$ & $-0.8(-8.5 ; 7.0)$ \\
\hline \multirow[t]{6}{*}{ Foley vs DVI } & Time to vaginal & Cromi [16] & $26.1(0.76)$ & $18.2(0.80)$ & $7.8(5.7 ; 10.0)$ \\
\hline & delivery & Cromi [17] & $18.8(0.53)$ & $19.9(0.95)$ & $-1.1(-3.2 ; 1.0)$ \\
\hline & Meta-analysis & & $22.4(3.62)$ & $18.99(0.83)$ & $3.4(-5.4 ; 12.1)$ \\
\hline & Time to onset of & Cromi $[16]$ & $21.3(0.71)$ & $15.2(0.69)$ & $6.1(4.1 ; 8.0)$ \\
\hline & active labor & Cromi [17] & $15.6(0.44)$ & $16.6(0.87)$ & $-1.0(-2.9 ; 0.9)$ \\
\hline & Meta-analysis & & $18.42(2.85)$ & $15.81(2.5)$ & $2.5(-4.4 ; 9.5)$ \\
\hline
\end{tabular}

\begin{tabular}{llll}
\hline Comparison & Outcome analyzed & Numerical values (\%) & CI
\end{tabular}

Time-to-event data used in the model: reduction/increase related to the use of misoprostol vaginal insert presented as the percentage of time (in hours) of the comparator's arm

\begin{tabular}{|c|c|c|c|}
\hline MVI vs DVI & Time to (active) labor & 65.1 & $(53 ; 77.1)$ \\
\hline MVI vs D gel & & 48.6 & $(39.6 ; 57.6)$ \\
\hline MVI vs D tab & & 70.5 & $(57.4 ; 83.6)$ \\
\hline MVI vs Foley & & 56.1 & $(45.7 ; 66.5)$ \\
\hline MVI vs DVI & Time of labor $(\mathrm{TtD}-\mathrm{TtL})^{\mathrm{b}}$ & 66.2 & $(44 ; 88.4)$ \\
\hline MVI vs D gel & & 61.6 & $(41 ; 82.3)$ \\
\hline MVI vs D tab & & 73.8 & $(49.1 ; 98.5)$ \\
\hline
\end{tabular}

$S E$ standard error, $C I$ confidence interval, $R C T$ randomized controlled trial, $D V I$ dinoprostone vaginal insert, $M V I$ misoprostol vaginal insert, Dgel dinoprostone cervical gel, Dtab dinoprostone tablets

a Calculated on the basis of data available in the publications

b Calculated as difference between time to delivery $(\mathrm{TtD})$ and time to labor ( $\mathrm{TtL})$

broad spectrum of the safety profile. When compared to DVI, use of MVI was related to significantly higher risk of uterine tachysystole, tocolytic administration and meconium in amniotic fluid. No difference in postpartum hemorrhage was observed. Occurrence of chorioamnionitis was significantly lower for MVI. For Dgel, an indirect comparison was possible to perform only for postpartum hemorrhage. The result was not statistically significant; nevertheless, the direction of the result was in favor of MVI. It was impossible to 
Table 3 Percentage of patients with vaginal delivery, with oxytocin administration and with adverse events

\begin{tabular}{|c|c|c|c|c|}
\hline $\begin{array}{l}\text { Outcome analyzed } \\
\text { (proportion of patients) }\end{array}$ & Comparison & RR, $95 \% \mathrm{CI}$ & $\begin{array}{l}\text { Comparator's } \\
\text { arm }\end{array}$ & MVI arm \\
\hline \multirow[t]{4}{*}{ Vaginal delivery } & MVI vs DVI & $1.02(0.95 ; 1.09)$ & $72.58 \%$ & $73.85 \%$ \\
\hline & MVI vs D gel & $1.02(0.89 ; 1.17)$ & $79.43 \%$ & $80.86 \%$ \\
\hline & MVI vs D tab & $1.03(0.88 ; 1.21)$ & $78.00 \%$ & $80.42 \%$ \\
\hline & MVI vs Foley & $0.96(0.87 ; 1.06)$ & $73.73 \%$ & $70.85 \%$ \\
\hline \multirow[t]{4}{*}{ Oxytocin use } & MVI vs DVI & $0.65(0.59 ; 0.71)$ & $74.07 \%$ & $48.07 \%^{*}$ \\
\hline & MVI vs D gel & $0.32(0.22 ; 0.45)$ & $40.17 \%$ & $12.77 \%^{*}$ \\
\hline & MVI vs D tab & $0.66(0.49 ; 0.89)$ & $48.00 \%$ & $31.82 \% *$ \\
\hline & MVI vs Foley & $0.50(0.39 ; 0.62)$ & $84.61 \%$ & $41.88 \%^{*}$ \\
\hline \multirow[t]{4}{*}{ Uterine tachysystole } & MVI vs DVI & $3.34(2.20 ; 5.07)$ & $3.97 \%$ & $13.27 \% *$ \\
\hline & MVI vs D gel & No data & No data & No data \\
\hline & MVI vs D tab & No data & No data & No data \\
\hline & MVI vs Foley & $39.91(5.02 ; 317.50)$ & $0.17 \%$ & $6.72 \%^{*}$ \\
\hline \multirow[t]{5}{*}{ Tocolytic administration } & MVI vs DVI & $2.97(1.96 ; 4.50)$ & $4.12 \%$ & $12.24 \%^{*}$ \\
\hline & MVI vs D gel & No data & No data & No data \\
\hline & MVI vs D tab & No data & No data & No data \\
\hline & MVI vs Foley & No data & No data & No data \\
\hline & MVI vs Oxytocin & No data & No data & No data \\
\hline \multirow[t]{4}{*}{ Meconium in amniotic fluid } & MVI vs DVI & $1.31(1.02 ; 1.68)$ & $13.53 \%$ & $17.70 \%^{*}$ \\
\hline & MVI vs D gel & No data & No data & No data \\
\hline & MVI vs D tab & No data & No data & No data \\
\hline & MVI vs Foley & $0.97(0.53 ; 1.78)$ & $5.92 \%$ & $5.72 \%$ \\
\hline \multirow[t]{4}{*}{ Chorioamnionitis } & MVI vs DVI & $0.65(0.44 ; 0.96)$ & $8.68 \%$ & $5.60 \% *$ \\
\hline & MVI vs D gel & No data & No data & No data \\
\hline & MVI vs D tab & No data & No data & No data \\
\hline & MVI vs Foley & $0.94(0.39 ; 2.24)$ & $5.41 \%$ & $5.08 \%$ \\
\hline \multirow[t]{4}{*}{ Postpartum hemorrhage } & MVI vs DVI & $1.05(0.69 ; 1.60)$ & $5.88 \%$ & $6.19 \%$ \\
\hline & MVI vs D gel & $0.57(0.25 ; 1.28)$ & $6.98 \%$ & $3.96 \%$ \\
\hline & MVI vs D tab & No data & No data & No data \\
\hline & MVI vs Foley & $0.88(0.39 ; 1.98)$ & $7.94 \%$ & $7.00 \%$ \\
\hline
\end{tabular}

CI confidence interval, $M V I$ misoprostol vaginal insert, $D V I$ dinoprostone vaginal insert, Dgel dinoprostone cervical gel, Dtab dinoprostone tablets, $R R$ relative risk

${ }^{*}$ Statistically significant 
assess MVI safety when compared to Dtab because of lack of data in Rabl [15]. For MVI versus Foley no differences in risk of meconium in amniotic fluid, chorioamnionitis and postpartum hemorrhage were observed; however, the direction of outcomes indicated lower risk of these events in the MVI arm. For uterine tachysystole the outcome was unfavorable for MVI, with statistical significance achieved.

To calculate the risk of particular end-point occurrence for MVI arm, calculated RR and risk of the events in the comparator arms were used. As a basic outcome the numerical value of assessed parameters was considered, while statistical significance of the outcome was considered as conservative assumption (Tables 2, 3). This approach was reasonable, since the main purpose of the project was to estimate anticipated costs related to MVI use in place of alternative technologies in clinical practice in IOL. Therefore, the direction of the outcome, even if not statistically significant, was relevant to reflect differences in costs.

\section{Results of the Retrospective Questionnaire}

Market shares of interventions used in IOL in 5 countries of interest revealed a lack of one most commonly chosen option across countries. Prostaglandins were used in the vast majority of cases of IOL in Austria and Slovakia. In Poland only $2 \%$ of IOL was supported by one of the prostaglandins (Dgel). Oxytocin was used in almost all cases of IOL in Romania and often used in Poland and Russia. Balloon catheter was used most often in Poland (Table 4).

Costs applied in the economic model are presented in Table 4.

The hourly cost of stay in wards varied both between countries and ward types. Generally, the most expensive was the labor ward with higher hourly rate for cesarean than vaginal delivery. The cost of stay on antenatal ward was the lowest one (with exception of Austria). On average, Austria and Slovakia had the highest hourly rates whereas Russia had the lowest (Table 4).

The length of patient stay on the hospital wards was connected with the local clinical practice. In general, the patient's stay on the postnatal ward was the longest one. In all countries except for Romania, cesarean delivery was related to a longer length of stay than vaginal delivery (the difference was between 4.75 and $74.50 \mathrm{~h}$ ). In Russia, patient stayed about 11.92 and $16.67 \mathrm{~h}$ in total on hospital wards (for vaginal and cesarean delivery, respectively); whereas, at the other end the scale, is Slovakia with 130 and $168.75 \mathrm{~h}$ (Fig. 2).

Time spent by medical staff per patient was reported separately for each specialist. The differences in time devoted by medical staff across countries were noticeable, as it varied from 30 to a maximum of $560 \mathrm{~min}$ per nurse (Austria-Romania) and from 155 to 840 min per obstetrician-gynecologist

(Austria-Russia) (Fig. 3).

\section{Results of the Cost-Consequences Model}

Results of the cost-consequences model were calculated as cost differences per single patient, separately for two variants of clinical data implementation: (1) numerical and (2) statistically significant values. The results of the model are presented in Table 5.

Use of MVI in most scenarios was related to a reduction in time consumed by hospital staff, mostly for midwives and obstetrician-gynecologists, and a reduction in 
Table 4 Economic parameters used in the analysis

\begin{tabular}{|c|c|c|c|c|c|}
\hline $\begin{array}{l}\text { Interventions used in labor } \\
\text { induction }\end{array}$ & Austria & Poland & Slovakia & Romania & Russia \\
\hline \multicolumn{6}{|c|}{ Market share of interventions used in labor induction } \\
\hline Dinoprostone: cervical gel & - & $2 \%$ & $3.5 \%$ & - & $40 \%$ \\
\hline Dinoprostone: vaginal tablets & $30 \%$ & - & $90 \%$ & - & - \\
\hline Dinoprostone: vaginal insert & $60 \%$ & - & - & - & - \\
\hline Oxytocin (intravenous) & $10 \%$ & $37 \%$ & $3 \%$ & $95.9 \%$ & $25 \%$ \\
\hline Baloon catheter (e.g., Foley catheter) & - & $60 \%$ & - & - & $20 \%$ \\
\hline Other & - & $1 \%$ & $3.5 \%$ & $4.1 \%$ & $15 \%$ \\
\hline \multicolumn{6}{|l|}{ Costs-hospital perspective $(€)$} \\
\hline \multicolumn{6}{|l|}{ Category of cost } \\
\hline \multicolumn{6}{|l|}{ Intervention used in labor induction } \\
\hline Dinoprostone: cervical gel & - & $\begin{array}{l}29.21 /(0.5 \mathrm{mg} ; 3 \mathrm{~g} \\
\text { gel })\end{array}$ & $\begin{array}{l}3.33 / \text { gel } \\
(1 \mathrm{~g})\end{array}$ & - & $\begin{array}{l}6.67 / \mathrm{gel} \\
\quad(1 \mathrm{~g})\end{array}$ \\
\hline Dinoprostone: vaginal tablets & $3.75 / 1 \mathrm{mg}$ & - & $2.00 / 1 \mathrm{mg}$ & - & - \\
\hline Dinoprostone: vaginal insert & $\begin{array}{l}64.00 / \\
1 \text { insert }\end{array}$ & - & - & - & - \\
\hline Oxytocin (intravenous) & $0.356 / 1 \mathrm{IU}$ & $0.08 / 1 \mathrm{IU}$ & $0.50 / 1 \mathrm{IU}$ & $\begin{array}{l}0.14 / \\
1 \mathrm{IU}\end{array}$ & $1.00 / 1 \mathrm{IU}$ \\
\hline Baloon catheter (e.g., Foley catheter) & - & $0.31 / 1$ unit & - & - & - \\
\hline $\begin{array}{l}\text { Infusion fluid required for dissolving } \\
\text { the oxytocin (per infusion) }\end{array}$ & 0.29 & 0.47 & 2.00 & 0.45 & 2.00 \\
\hline \multicolumn{6}{|c|}{ Wages of medical staff (average wages per hour) } \\
\hline Nurse & 40.20 & 7.13 & 2.00 & 1.57 & 1.50 \\
\hline Midwife & 46.20 & 7.27 & 2.50 & 3.37 & 2.50 \\
\hline Obstetrician-gynecologist & 79.20 & 14.92 & 5.00 & 6.74 & 6.00 \\
\hline Anesthesiologist & 79.20 & 31.97 & 5.00 & 6.74 & 5.00 \\
\hline Neonatologist & 79.20 & 34.83 & 5.00 & 6.74 & 10.00 \\
\hline $\begin{array}{l}\text { Other (psychologist-Poland; } \\
\text { medical nurse-Romania) }\end{array}$ & - & 8.23 & - & 3.37 & - \\
\hline \multicolumn{6}{|c|}{ Cost per hour in the wards (including all costs of procedures, disposables and non-medical resources) } \\
\hline Antenatal ward & 67.33 & 4.83 & 20.00 & 7.19 & 10.00 \\
\hline Labor ward_-vaginal delivery & 24.58 & 17.79 & 70.00 & 11.69 & 15.00 \\
\hline Labor ward-cesarean delivery & 63.75 & 146.12 & 100.00 & 26.52 & 20.00 \\
\hline Postnatal ward & 67.33 & 4.83 & 30.00 & 13.48 & 10.00 \\
\hline
\end{tabular}


Table 4 continued

\begin{tabular}{|c|c|c|c|c|c|}
\hline $\begin{array}{l}\text { Interventions used in labor } \\
\text { induction }\end{array}$ & Austria & Poland & Slovakia & Romania & Russia \\
\hline \multicolumn{6}{|c|}{ Cost of the adverse events (per event)* } \\
\hline Uterine tachysystole & - & 1542.37 & 20.00 & 0.22 & 35.00 \\
\hline Tocolytic administration & - & 1573.20 & 20.00 & 627.29 & 300.00 \\
\hline Meconium in amniotic fluid & - & 1612.78 & 200.00 & 10.11 & 100.00 \\
\hline Chorioamnionitis & - & 761.55 & 100.00 & 197.75 & 110.00 \\
\hline Postpartum hemorrhage & - & 4274.77 & 150.00 & 20.39 & 740.00 \\
\hline
\end{tabular}

Data obtained from the questionnaire study; year of the costs-2014

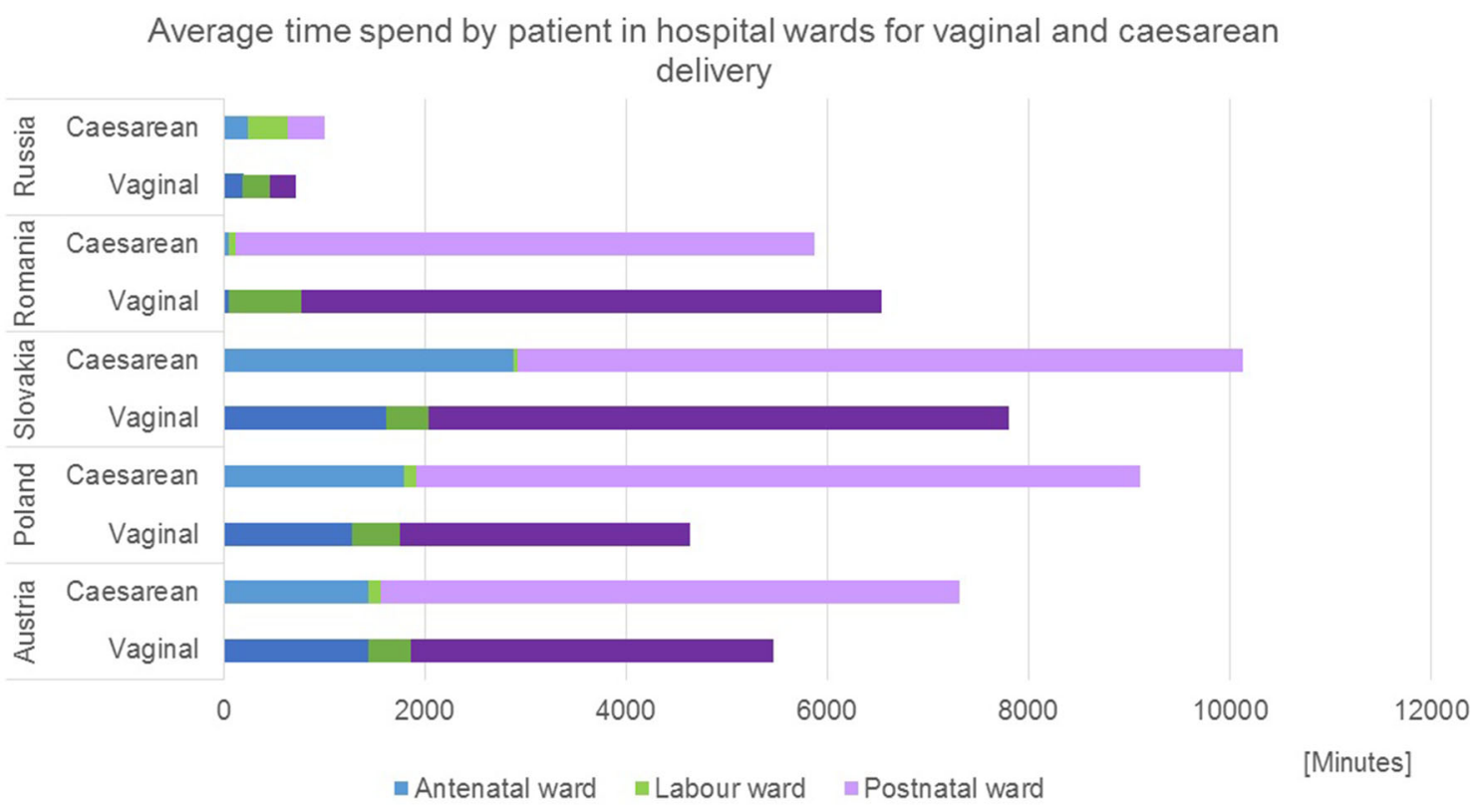

Fig. 2 Average time spend by patient in hospital wards for vaginal and cesarean delivery

the length of patients' stay in hospital wards, especially for the phase between induction and labor and during labor itself (Table 5).

Using MVI in place of prostaglandin E2 was less costly in almost all comparisons. The highest cost difference was observed in Austria, where MVI generated savings between $€ 575.15$ and $€ 713.42$ per patient. Both numerical and statistically significant scenarios showed savings. The exception was Russia, where the total healthcare cost derived from using Dgel was a slightly lower than for MVI in the model variant with statistically significant values. However, the difference was small ( $€ 5.36$ per patient in favor of Dgel). For Poland, the introduction of MVI in IOL generated additional savings in comparison to Dgel, while the comparison to Foley was related to extra costs, due mostly to the very low cost of the Foley catheter. 


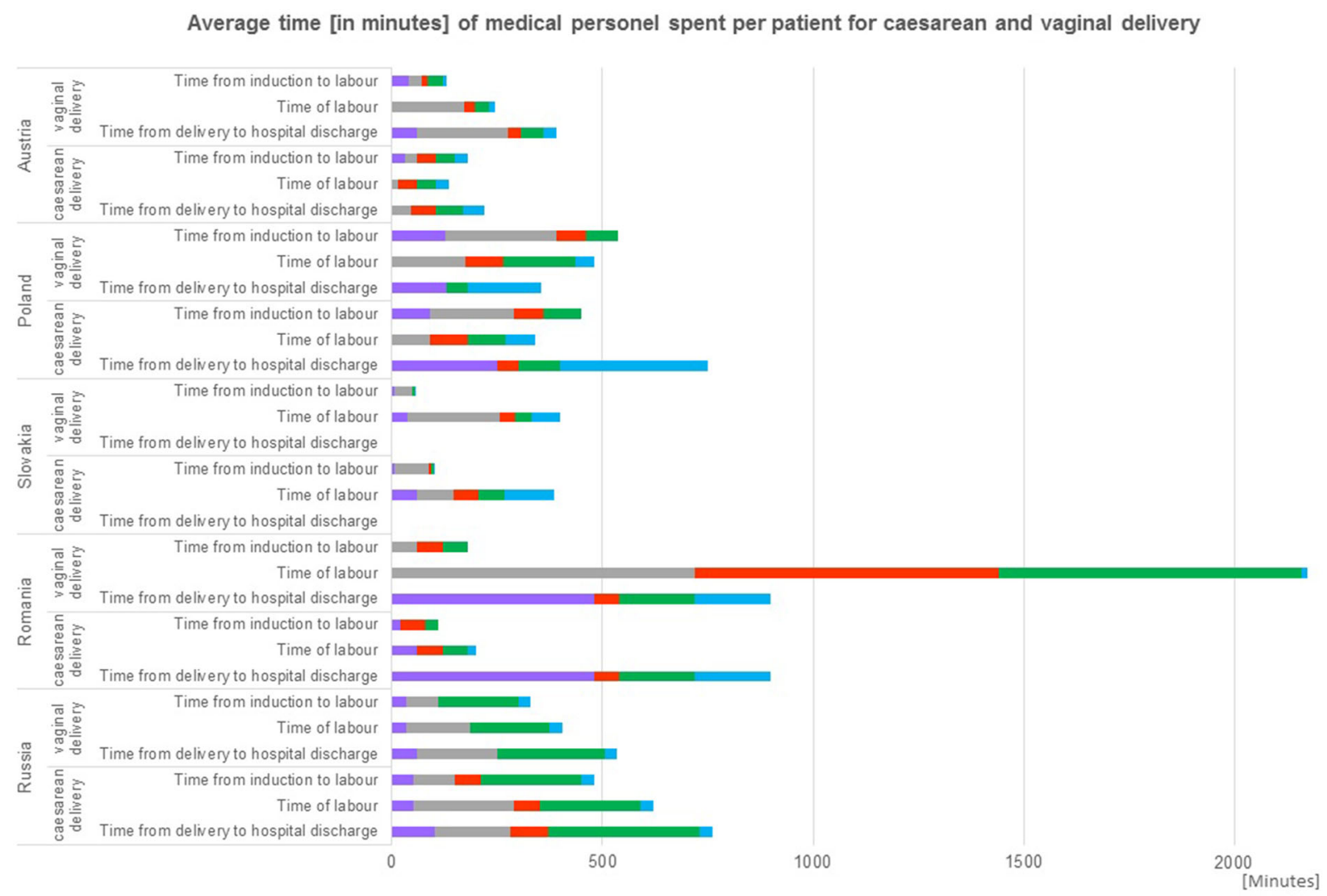

Fig. 3 Average time of medical staff spent for cesarean and vaginal delivery per single patient

\section{DISCUSSION}

The model was designed to connect clinical data on effectiveness and safety with RWD on costs and resource utilization. Data on MVI and the alternative technologies effectiveness was obtained from identified randomized clinical trials. Data on costs and consequences related to MVI use was obtained from collected questionnaires.

Based on the results of our research MVI had a statistically significant shorter time to delivery and to active labor compared to DVI (Wing [9]). The indirect comparison showed that MVI had a similar effectiveness and safety profile compared to Dgel and Dtab. Nevertheless, use of MVI was related to a reduction in time to delivery between $28 \%$ and $47 \%$, when compared to Dtab and Dgel, respectively. MVI provided also a reduction in time from induction to labor.

The results showed that IOL with MVI generates savings, from a hospital perspective, in the majority of comparisons performed with other prostaglandins. Unsurprisingly, the difference in favor of MVI originated in the longer time of the induction phase and the labor itself for other prostaglandins. A shorter stay of the patient in the ward is directly connected with a shortening of the time of medical staff care.

We have identified two systematic reviews, which assess prostaglandins in IOL Thomas [22] and Alfirevic [23]. Unfortunately, neither presents data for MVI. Only the most recent network meta-analysis (Alfirevic [24]) includes 
Table 5 Results of cost-consequences model for comparisons: misoprostol vaginal insert vs standard of care

\begin{tabular}{llll}
\hline Country & Comparison & Numerical values* & $\begin{array}{l}\text { Statistically } \\
\text { significant values* }\end{array}$ \\
\hline Austria & MVI vs DVI & -713.42 & -684.80 \\
& MVI vs D tab & -575.13 & -649.24 \\
Poland & MVI vs D gel & -302.38 & -151.00 \\
& MVI vs Foley & 24.30 & 87.62 \\
Romania & $-\quad-$ & - \\
Russia & MVI vs D gel & -23.04 & 5.36 \\
Slovakia & MVI vs D tab & -198.35 & -233.39 \\
& MVI vs D gel & -425.12 & -387.67 \\
\hline
\end{tabular}

Country

Comparison Stay in the ward

Midwife work time

Obstetrician-gynecologist work time

Time differences Misodel vs comparator per one patient (hrs, numerical values)*

Vaginal delivery

\begin{tabular}{lllll} 
Austria & MVI vs DVI & $-11.2 /-11.2$ & $-1.8 /-1.8$ & $-0.3 /-0.3$ \\
& MVI vs D tab & $-9.4 /-11.4$ & $-1.5 /-2$ & $-0.3 /-0.3$ \\
Poland & MVI vs D gel & $-20 /-19.5$ & $-4.6 /-4.5$ & $-2.1 /-1.9$ \\
& MVI vs Foley & $-10.3 /-8$ & $-2.7 /-2.1$ & $-1.8 /-1.3$ \\
\multirow{2}{*}{ Romania } & - & - & - & - \\
Russia & MVI vs D gel & $-3.5 /-3.2$ & $-1.3 /-1.2$ & $-2.7 /-2.6$ \\
Slovakia & MVI vs D tab & $-8.9 /-10.8$ & $-1.5 /-2$ & $-0.1 /-0.1$ \\
& MVI vs D gel & $-18.1 /-17.8$ & $-3 /-2.8$ & $-0.1 /-0.1$
\end{tabular}

Cesarean delivery

$\begin{array}{lllll}\text { Austria } & \text { MVI vs DVI } & -8.4 /-8.4 & -0.2 /-0.2 & -0.3 /-0.3 \\ & \text { MVI vs D tab } & -7.1 /-8.4 & -0.1 /-0.2 & -0.2 /-0.3 \\ \text { Poland } & \text { MVI vs D gel } & -15.4 /-15.4 & -1.7 /-1.7 & -0.8 /-0.8 \\ & \text { MVI vs Foley } & -13.2 /-10.5 & -1.5 /-1.2 & -0.7 /-0.5 \\ \text { Romania } & - & - & - & - \\ \text { Russia } & \text { MVI vs D gel } & -2.1 /-2.1 & -0.9 /-0.9 & -2.1 /-2.1 \\ \text { Slovakia } & \text { MVI vs D tab } & -14.2 /-16.8 & -0.4 /-0.5 & 0.0 / 0.0 \\ & \text { MVI vs D gel } & -24.7 /-24.7 & -0.7 /-0.7 & -0.1 /-0.1\end{array}$

Cost differences per one patient from hospital perspective $(€)$

$M V I$ misoprostol vaginal insert, $D V I$ dinoprostone vaginal insert, Dtab dinoprostone tablets, Dgel dinoprostone cervical gel

${ }^{*}$ In case of costs negative value means additional saving. Negative values of time indicates reduction in time related to Misodel use (positive value indicates additional time related to Misodel use) 
MVI as one of prostaglandins used in IOL. The findings of Alfirevic [24] are consistent with the results of our relative effectiveness assessment with regard to our interventions.

There are only a small number of economic evaluations for prostaglandin used in IOL (Petrou [25] and Baaren [26]). We cannot relate our results to these studies, because of their scope. We did not find any analysis that assessed costs and effectiveness of using MVI in IOL. In this sense, our analysis is the only economic evaluation which gathers both clinical effectiveness and RWD to estimate the costs and benefits from the use of MVI in place of the current clinical practice.

Our study is especially important, as it presents costs related to IOL from hospital perspective. Cost and resource use data are very often difficult to obtain, therefore this paper gives opportunity to access them. It may be also treated as an overview of the standards applied in other medical centers. Since cost of agents used in IOL is usually incurred by the hospitals management, our findings may help in making decisions on the optimal distribution of limited health care funds.

Unfortunately, the model does not embrace all possible alternative technologies used in IOL such as misoprostol tablets or oxytocin. Misoprostol tablets were not considered because of the off-label indication. Taking into account accessibility to prostaglandins, which are designed to our target population, we assumed that the clinical practice will displace off-label technologies from the use. As a result of the questionnaire study oxytocin was indicated in many countries. Although we tried to perform reliable comparison of MVI vs oxytocin, design of the clinical trials could lead to misleading results. The considerable limitation of the study was limited number of collected questionnaires. Centers did not provide any data about survey respondents.

To estimate the costs associated with the Foley catheter, data from clinical expert was collected. It should be realized that they may be underestimated. By including an additional labor costs of Foley catheter placement, it may be find the Foley catheter and MVI are more similar in cost.

Our results are the only estimation on how real practice may look like, although results need to be interpreted with caution.

\section{CONCLUSION}

To sum up, IOL with the use of MVI generated savings from a hospital perspective in most countries and scenarios, in comparison to alternative technologies.

\section{ACKNOWLEDGMENTS}

Sponsorship, article processing charges, and the open access charge for this study were funded by Ferring Pharmaceuticals Poland. All authors had full access to all of the data in this study and take complete responsibility for the integrity of the data and accuracy of the data analysis. All named authors meet the International Committee of Medical Journal Editors (ICMJE) criteria for authorship for this manuscript, take responsibility for the integrity of the work as a whole, and have given final approval for the version to be published. We would like to thank Prof. Tomasz Opala for clinical advice and medical support, Marije van Weelden, Wojciech Izbicki, Piotr Ziajkowski, Natalia Wiśniewska and Agnieszka Żyła for their assistance and contribution. 
Disclosures. Adam Bierut is an employee of Ferring pharmaceuticals. Jadwiga Dowgiałło-Smolarczyk is an employee of Ferring pharmaceuticals. Izabela Pieniążek, Jarosław Stelmachowski, Kinga Pacocha, Maciej Sobkowski, Oleg R. Baev and Jacek Walczak have nothing to disclose.

Compliance with Ethics Guidelines. This article is based on previously conducted studies and does not involve any new studies of human or animal subjects performed by any of the authors.

Open Access. This article is distributed under the terms of the Creative Commons Attribution-NonCommercial 4.0 International License (http://creativecommons.org/licenses/ by-nc/4.0/), which permits any noncommercial use, distribution, and reproduction in any medium, provided you give appropriate credit to the original author(s) and the source, provide a link to the Creative Commons license, and indicate if changes were made.

\section{REFERENCES}

1. NICE Induction of labour. Clinical Guideline July 2008. https://www.nice.org.uk/Guidance/cg70. Accessed Feb 2014.

2. Misodel Summary of Product Characteristic. http:// pub.rejestrymedyczne.csioz.gov.pl/ProduktSzczegoly. aspx?id=30708. Accessed 21 Mar 2014.

3. Higgins JPT, Green S, editors. Cochrane handbook for systematic reviews of interventions version 5.1.0 [updated March 2011]. The Cochrane Collaboration; 2011. Available from http://www. cochrane-handbook.org.

4. Huedo-Medina TB, Sánchez-Meca J, Marín-Martínez $\mathrm{F}$, Botella J. Assessing heterogeneity in meta-analysis: Q statistic or I2 index? Psychol Methods. 2006;11(2):193-206.

5. Bucher HC, Guyatt GH, Griffith LE, Walter SD. The results of direct and indirect treatment comparisons in meta-analysis of randomized controlled trials. J Clin Epidemiol. 1997;50(6):683-91.

6. Haute Autorité de Santé. Indirect comparisons. Methods and validity. SUMMARY REPORT, July 2009.

7. Song F. What is indirect comparison? NPR09/1098. http://www.medicine.ox.ac.uk/bandolier/painres/ download/whatis/What_is_ind_comp.pdf. Accessed 21 Mar 2014.

8. Song F, Altman DG. Validity of indirect comparison for estimating efficacy of competing interventions: empirical evidence from published meta-analyses. BMJ. 2003;326(7387):472.

9. Wing DA, Brown R, Plante LA, Miller H, Rugarn O, Powers BL. Misoprostol vaginal insert and time to vaginal delivery: a randomized controlled trial. Obstet Gynecol. 2013;122(2 Pt 1):201-9.

10. Facchinetti F, Venturini P, Verocchi G, Volpe A. Comparison of two preparations of dinoprostone for pre-induction of labour in nulliparous women with very unfavourable cervical condition: a randomised clinical trial. Eur J Obstet Gynecol Reprod Biol. 2005;119(2):189-93.

11. Facchinetti F, Venturini P, Fazzio $M$, Volpe A. Elective cervical ripening in women beyond the 290th day of pregnancy: a randomized trial comparing 2 dinoprostone preparations. J Reprod Med. 2007;52(10):945-9.

12. Marconi AM, Bozzetti P, Morabito A, Pardi G. Comparing two dinoprostone agents for cervical ripening and induction of labor: a randomized trial. Eur J Obstet Gynecol Reprod Biol. 2008;138(2):135-40.

13. Stewart JD, Rayburn WF, Farmer KC, Liles EM, Schipul AH Jr, Stanley JR. Effectiveness of prostaglandin E2 intracervical gel (Prepidil), with immediate oxytocin, versus vaginal insert (Cervidil) for induction of labor. Am J Obstet Gynecol. 1998;179(5):1175-80.

14. Strobelt N, Meregalli V, Ratti M, Mariani S, Zani G, Morana S. Randomized study on removable PGE2 vaginal insert versus PGE2 cervical gel for cervical priming and labor induction in low-Bishop-score pregnancy. Acta Obstet Gynecol Scand. 2006;85(3):302-5.

15. Rabl M, Joura EA, Yücel Y, Egarter C. A randomized trial of vaginal prostaglandin E2 for induction of labor. Insert vs. tablet. J Reprod Med. 2002;47(2):115-9.

16. Cromi A, Ghezzi F, Agosti M, Serati M, Uccella S, Arlant V, Bolis P. Is transcervical Foley catheter 
actually slower than prostaglandins in ripening the cervix? A randomized study. Am J Obstet Gynecol. 2011;204(4):338.e1-7.

17. Cromi A, Ghezzi F, Uccella S, Agosti M, Serati M, Marchitelli G, Bolis P. A randomized trial of preinduction cervical ripening: dinoprostone vaginal insert versus double-balloon catheter. Am J Obstet Gynecol. 2012;207(2):125.e1-7.

18. Edwards RK, Szychowski JM, Berger JL, Petersen M, Ingersoll M, Bodea-Braescu AV, Lin MG. Foley catheter compared with the controlled-release dinoprostone insert: a randomized controlled trial. Obstet Gynecol. 2014;123(6):1280-7.

19. Jozwiak M, Rengerink KO, Ten Eikelder M, et al. Foley catheter or prostaglandin E2 inserts for induction of labour at term: an open-label randomized controlled trial (PROBAAT-P trial) and systematic review of literature. Eur J Obstet Gynaecol Reprod Biol. 2013;170:137-45.

20. Pennell CE, Henderson JJ, O’Neill MJ, McChlery S, Doherty DA, Dickinson JE. Induction of labour in nulliparous women with an unfavorable cervix: a randomised controlled trial comparing double and single balloon catheters and PGE2 gel. BJOG. 2009;116:1443-52.

21. Salim R, Zafran N, Nachum Z, Garmi G, Kraiem N, Shalev E. Single-balloon compared with double-balloon catheters for induction of labor: a randomized controlled trial. Obstet Gynecol. 2011;118:79-86.

22. Thomas J, Fairclough A, Kavanagh J, Kelly AJ. Vaginal prostaglandin (PGE2 and PGF2a) for induction of labour at term. Cochrane Database Syst Rev. 2014;6:CD003101.

23. Alfirevic Z, Aflaifel N, Weeks A. Oral misoprostol for induction of labour. Cochrane Database Syst Rev. 2014;6:CD001338.

24. Alfirevic Z, Keeney E, Dowswell T, Welton NJ, Dias $S$, Jones LV, Navaratnam K, Caldwell DM. Labour induction with prostaglandins: a systematic review and network meta-analysis. BMJ. 2015;5(350):h217. doi:10.1136/bmj.h217.

25. Petrou S, Taher S, Abangma G, Eddama O, Bennett P. Cost-effectiveness analysis of prostaglandin E2 gel for the induction of labour at term. BJOG. 2011;118(6):726-34.

26. van Baaren GJ, Jozwiak M, Opmeer BC, Oude Rengerink K, Benthem M, Dijksterhuis MG, van Huizen ME, van der Salm PC, Schuitemaker NW, Papatsonis DN, Perquin DA, Porath M, van der Post JA, Rijnders RJ, Scheepers HC, Spaanderman M, van Pampus MG, de Leeuw JW, Mol BW, Bloemenkamp KW. Cost-effectiveness of induction of labour at term with a Foley catheter compared to vaginal prostaglandin $\mathrm{E}_{2}$ gel (PROBAAT trial). BJOG. 2013;120(8):987-95. 